\title{
Hidrogeoquímica do Sistema Aquífero Serra Geral na região do Alto Rio Uru- guai, Noroeste do Rio Grande do Sul e sua relação espacial com a tectônica rúptil
}

\author{
Gustavo Garcia da CUNHA ${ }^{1}$, Ari ROISENBERG ${ }^{1}$, Fernando Hepp PULGATI ${ }^{2}$ \& Marcos Alexandre \\ FREITAS $^{3}$
}

1 Instituto de Geociências, Universidade Federal do Rio Grande do Sul.Av. Bento Gonçalves, 9500, CEP 91.540-000, Porto Alegre, RS, Brasil. E-mails: ggcunha@gmail.com, ari.roisenberg@ufrgs.br.

2 Instituto de Matemática, Universidade Federal do Rio Grande do Sul.Av. Bento Gonçalves, 9500, CEP 91.540-000, Porto Alegre, RS, Brasil. E-mail: pulgati@ufrgs.br.

3 Serviço Geológico do Brasil, Superintendência Regional de Porto Alegre. Rua Banco da Província, no 105, CEP 90840-030, Porto Alegre, RS, Brasil. E-mail: marcos.freitas@cprm.gov.br.

Recebido em 04/2014. Aceito para publicação em 01/2016.

Versão online publicada em 23/02/2016 (www.pesquisasemgeociencias.ufrgs.br)

\begin{abstract}
Resumo - 0 presente estudo visa contribuir para melhorar o conhecimento sobre o Sistema Aquífero Serra Geral (SASG), reconhecendo diferentes tipos geoquímicos de águas subterrâneas e testando a existência de relações com as estruturas tectônicas na região do Alto Rio Uruguai, Noroeste do Estado do Rio Grande do Sul. A metodologia utilizada envolveu a aquisição de dados de poços tubulares georreferenciados da região, traçado de lineamentos morfotectônicos por meio de imagens de satélite e filtragens em Sistema de Informações Geográficas (SIG), geração de mapas temáticos e análise estatística dos dados obtidos. Foram traçados 1.981 lineamentos tectônicos, sendo esses separados por padrões de direções. Os lineamentos de direção NE-E e NW-W são dominantes na área. A variação das Fácies hidrogeoquímicas demonstrou uma correlação positiva com a densidade de lineamentos. As Fácies CaMg e Águas Mistas apresentam características de baixo tempo de residência, estando provavelmente relacionadas à captação de águas associadas a áreas de recarga do SASG, sendo a primeira conectada com lineamentos de direção NE-E e N-NW e a segunda com a direção NW-W. A Fácies Na, relacionada com lineamentos de direção NE-E e NW-W, apresenta valores de $\mathrm{pH}$ alcalinos, baixa dureza e elevado teor de Sólidos Totais Dissolvidos (STD), que sugerem mistura com águas provenientes do Sistema Aquífero Guarani (SAG) subjacente. As Fácies FeK e F estão associadas possivelmente com zonas de recarga ascendente do SAG ou mesmo de aquíferos mais profundos, a primeira apresentando conexão com as direções NE-E e NW-W e a segunda com lineamentos N-NE.
\end{abstract}

Palavras-chaves: Fácies hidrogeoquímicas, aquífero fraturado, densidade de lineamentos.

Abstract-Hydrogeochemistry of the Serra Geral Aquifer System in the Alto Uruguai River REGION, NORTHWEST OF THE RIO GRANDE DO SUL STATE AND ITS SPATIAL RELATIONSHIP WITH THE BRITTLE TECTONICS.The present study aims to improve the knowledge about the hydrogeochemistry of the Serra Geral Aquifer System (SGAS), recognizing different geochemical Facies of groundwater and testing the existence of structural relationships conditioning the aquifer system in the Alto Uruguai River region, northwestern of the State of Rio Grande do Sul. The methodology was conducted through the initial acquisition of georeferenced database of tubular wells in the area, recovering of tectonic lineaments through satellite imagery and filtering in a Geographic Information System (GIS), generating thematic maps and statistical analysis of the database. 1.981 tectonic lineaments were drawn and separated by length and pattern directions. Short lineaments and directions NE-E and NW-W are dominant in the area. The variation of hydrogeochemical Facies shows positive correlation with the lineament density. The CaMg and Mixed Waters Facies exhibit characteristics of low residence time, related to recharge areas of SGAS, the first one being linked to NE-E and N-NW directions and the second one with the NW-W direction. The Na Facies is related to lineaments NE-E and NW-W directions and alkaline $\mathrm{pH}$ and high total dissolved solids (TDS) contents, suggesting mixing with waters from the underlying Guarani Aquifer System (GAS). The FeK and F Facies are related to areas of ascending recharge of GAS or even deeper aquifers, the first one presenting relationship with the NE-E and NW-W directions and the second strongly related to N-NE lineaments.

Keywords: Hydrogeochemical Facies, fractured rock aquifer, lineament density. 


\section{Introdução}

A demanda de recursos hídricos na região Sul do Brasil tem crescido de forma exponencial nas últimas décadas, em razão da rápida evolução industrial e agrícola, associada ao crescimento demográfico verificado principalmente nas médias e grandes cidades. Por outro lado, a degradação das águas superficiais, intimamente ligada à atividade antrópica, tem impulsionado pesquisas e estudos desenvolvidos sobre os sistemas Aquífero Serra Geral (SASG) e Aquífero Guarani (SAG) com o intuito de melhorar o conhecimento a respeito do potencial hídrico, qualidade e vulnerabilidade dos recursos subterrâneos.

Deve-se ponderar que aproximadamente $80 \%$ da demanda de água das cidades localizadas na área coberta pelo vulcanismo Mesozóico da Bacia do Paraná no Rio Grande do Sul é suprida pela exploração do SASG (Nanni, 2008). Este fato é justificado pela boa qualidade das águas e, por conseqüência, pelo relativamente baixo custo de tratamento, consorciado com a redução no valor da perfuração de poços, que tornou esta prática mais acessível. Desta forma, a gestão adequada das reservas hídricas subterrâneas pelos órgãos competentes é de fundamental importância para evitar futuros problemas de abastecimento público.

0 presente trabalho visa incrementar o conhecimento hidrogeoquímico do Sistema Aquífero
Serra Geral (SASG) na região do Alto Rio Uruguai, verificando a influência da tectônica na distribuição das diferentes fácies de águas subterrâneas.

\section{2 Área, materiais e métodos}

A área abrangida pelo presente estudo é localizada na região do Alto Rio Uruguai, Noroeste do Estado do Rio Grande do Sul, estando compreendida nas cartas topográficas 1:250.000 de Chapecó (Folha SG-22-Y-C) e Erechim (Folha SG-22-Y-D) da Diretoria de Serviço Geográfico (Fig. 1). Abrange um total de 107 municípios gaúchos, correspondendo à parte oriental da bacia hidrográfica dos rios Turvo-Santa Rosa-Santo Cristo, à parte Norte das bacias hidrográficas do Rio Passo Fundo e do Rio da Várzea e à parte ocidental da Bacia Hidrográfica dos rios Apuaê-Inhandava.

O clima na área segundo a classificação de Koeppen foi descrito como subtropical Cfa. Esta classificação considera a sazonalidade e os valores médios anuais e mensais da temperatura do ar e da precipitação. A região apresenta temperatura média do ar dos três meses mais frios compreendidas entre $-^{\circ} \mathrm{C}$ e $18^{\circ} \mathrm{C}$ e do mês mais quente superior a $22^{\circ} \mathrm{C}$, além de estações de verão e inverno bem definidas, com chuvas em todos os meses do ano. A precipitação pluviométrica média é de $1.550 \mathrm{~mm} /$ ano.

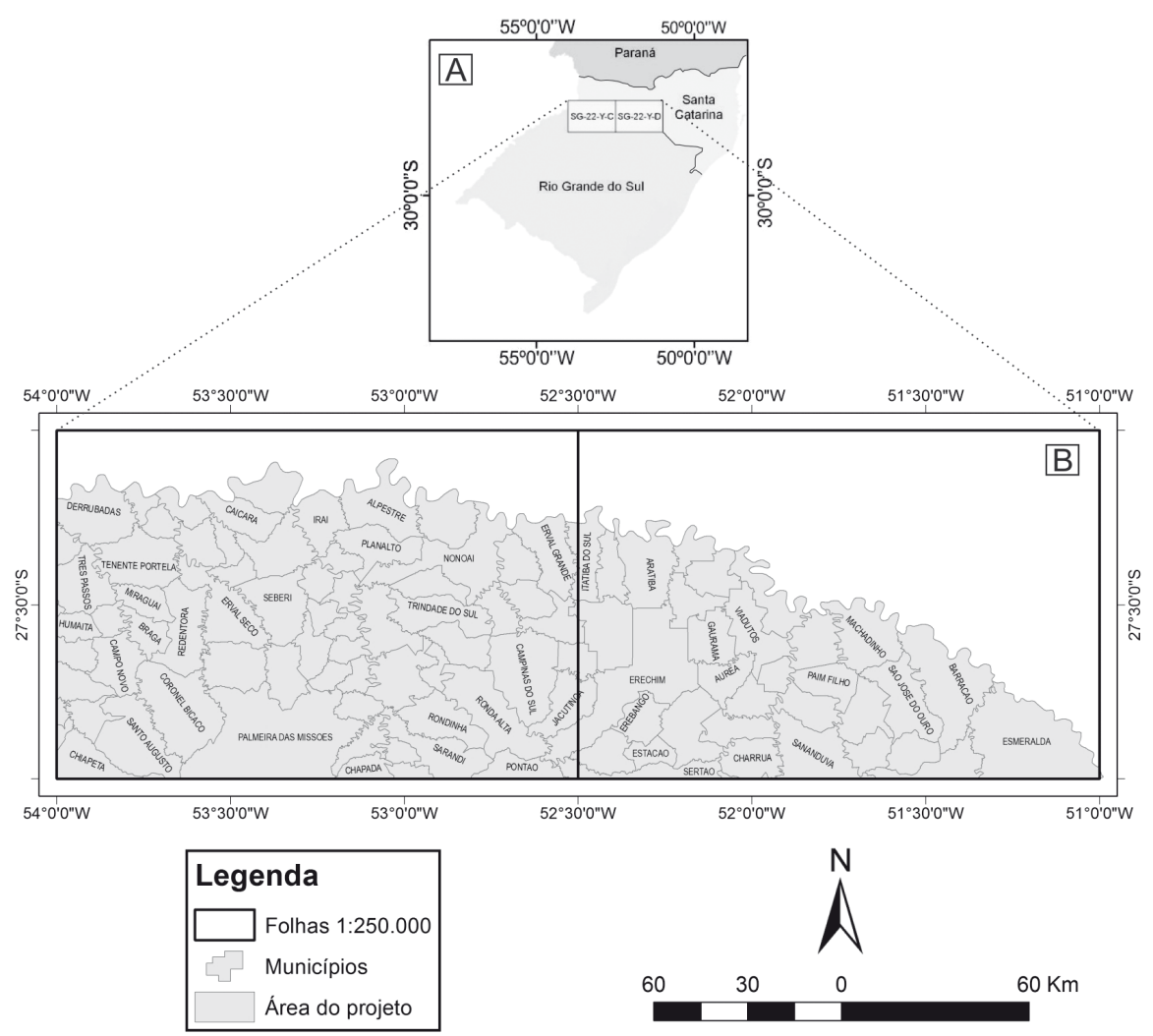

Figura 1. Mapa de localização. A) Mapa do Sul do Brasil, indicando as folhas Chapecó e Erechim; B) Detalhe da área de estudo. 


\subsection{Geologia e hidrogeologia}

A região em estudo está localizada na porção meridional da Bacia do Paraná sendo recoberta pelo pacote vulcânico da Formação Serra Geral, que possui espessuras de pelo menos $480 \mathrm{~m}$, como verificado a partir de sondagens em poços da Termas Três Arroios (480 m), Thermas Machadinho (817 m), Frigorífico Agrodaniele e Laticínios Tirol (960 m), ambos em Tapejara, e o poço da Companhia Riograndense de Saneamento (Corsan) na Barragem Arroio Ligeirinho em Erechim (868 m). Os arenitos da Formação Botucatu fazem parte, junto com a Formação Serra Geral, do Grupo São Bento, de idade Juro-Cretácea, estando localizados na base da pilha vulcânica.

0 pacote vulcânico é constituído dominantemente por basaltos a andesi-basaltos do tipo alto$-\mathrm{TiO}_{2}$ (fácies Paranapanema), enquanto basaltos baixo- $\mathrm{TiO}_{2}$ (fácies Esmeralda) aparecem na parte oriental da área, como definidos por Peate et al. $(1990,1992)$. Ao norte da região, próximo ao limite do Estado do Rio Grande do Sul com o Estado de Santa Catarina, são encontradas vulcânicas áci- das porfiríticas, fácies Chapecó, interdigitadas com vulcânicas básicas (CPRM, 2006).

Essa pilha vulcânica constitui o Sistema Aquífero Serra Geral, que mostra características hídricas francamente anisotrópicas e heterogêneas, com condições de armazenamento relacionadas às fraturas de contração e à tectônica rúptil. A zona vesicular de topo de derrame, às vezes contendo brechas, juntamente com a zona de disjunção tabular inferior, também pode ter boa capacidade de armazenamento hídrico (Freitas \& Machado, 2000), reconhecidas pela surgência de água em cortes de estrada.

O mapa hidrogeológico do Rio Grande do Sul (CPRM, 2005) define dois sistemas aquíferos na região em estudo, Sistema Aquífero Serra Geral I (SASG I) e Sistema Aquífero Serra Geral II (SASG II), distintos entre si pela capacidade hídrica, embora com características hidroquímicas semelhante (Fig. 2). A salinidade em geral é baixa (média de $200 \mathrm{mg} / \mathrm{l}$ ), enquanto águas mais salinas, sódicas e de elevado pH (entre 9 e 10) são aparentemente influenciadas por misturas com águas ascendentes do SAG.

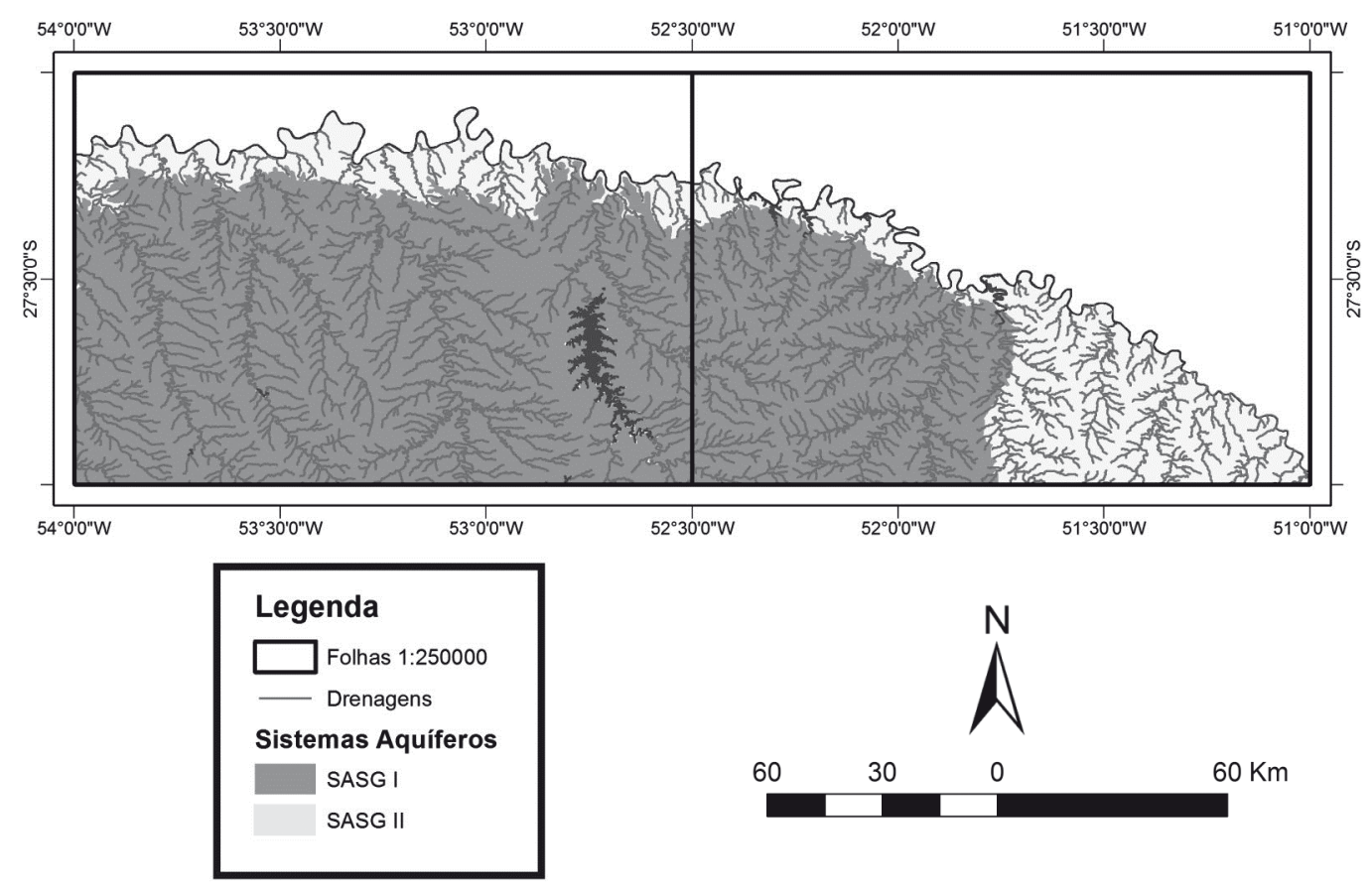

Figura 2. Mapa hidrogeológico da região (modificado de CPRM, 2005).

Lisbôa (1996) reconheceu três unidades hidrogeológicas distintas no SASG do Rio Grande do Sul: Abóbada Oeste Aplainada, Fachada Atlântica Dissecada e Abóbada Central Densamente Dissecada, esta última a única representada na região em estudo, localizada na Bacia do Alto Rio Uruguai. $\mathrm{O}$ autor registrou que as águas subterrâneas nas três unidades são dominantemente bicarbonatadas cálcicas e que águas sódicas ocasionais teriam origem na mistura de águas meteóricas com fluxos ascendentes do SAG subjacente.

Concentrações elevadas de fluoreto nas águas do SASG não são esperadas, face à baixa concentração deste elemento nas litologias do aquífero fraturado, e seu registro deve ser relacionado com a dinâmica de recarga ascendente no aquífero, que contribui para variações nas características físico-químicas das águas (Nanni et al., 2008). Segundo 
Lisbôa (1996), o uso demasiado do recurso hídrico subterrâneo pode acarretar prejuízos na qualidade das águas pela ascensão de águas mais profundas, através da trama fraturada do SASG.

Estudo integrado sobre o potencial hidrogeológico, vulnerabilidade e hidroquímica do SASG na Bacia Hidrográfica dos Rios Turvo-Santa Rosa-Santo Cristo, descreveu quatro tipos hidrogeoquímicos de águas do SASG (Freitas et al., 2012). 0 tipo I é representado por águas bicarbonatadas cálcicas ou magnesianas com valores mais baixos de $\mathrm{pH}$ e de Sólidos Totais Dissolvidos (STD), cujas características definem áreas de recarga do SASG com tempo de residência relativamente pequeno. As águas do tipo II são bicarbonatadas sódicas e apresentam valores de $\mathrm{pH}$ mais elevados, baixa dureza e valores de STD que sugerem misturas com águas do SAG subjacente. 0 Tipo III é definido por águas sulfatadas ou cloretadas cálcicas magnesianas com pH inferior a 7, baixos valores de STD e de fluoretos. As águas do tipo IV são sulfatadas ou cloretadas sódicas, de caráter alcalino, com elevados valores de STD, dureza e Flúor. Este tipo de água, também apresenta influência do aquífero Guarani e/ou de formações subjacentes.

\subsection{Métodos}

Na primeira etapa do estudo foi obtida documentação específica sobre poços tubulares da região, selecionando-se os poços que possuíam informações consistentes, como localização, perfis de sondagem e análises físico-químicas.

A análise tectônica foi realizada através de imagens de satélite a partir das quais foi confeccionada uma imagem de relevo sombreado, gerada a partir de um Modelo Digital de Terreno (MDT), que possibilita visualizar as diferenças de relevo em uma dada região, extraídos do projetoShuttle Radar TopographyMission- SRTM (USGS, 2000).

A imagem sombreada é gerada a partir de uma grade retangular sobre a qual é aplicado um modelo de iluminação. A partir dessa imagem é possível traçar lineamentos morfotectônicos, para tentar estabelecer padrões e eventuais blocos estruturais. As estruturas foram interpretadas em ambiente de Sistema de Informações Geográficas (SIG) com o uso do software ArcGIS ${ }^{\circledR}$ 9.3, sendo traçados os lineamentos geológicos, em escala $1: 250.000$, o que facilitou mapear estruturas regionais.

0 traçado de lineamentos em ambiente SIG permitiu que valores de coordenadas e azimutes fossem extraídos automaticamente, sendo criada uma tabela de atributos dos lineamentos, que for- neceu informações para tratamentos estatísticos posteriores.

O tratamento estatístico dos parâmetros tectônicos foi realizado com o programa RockWorks ${ }^{\circledR} 14$ para a aplicação de métodos estatísticos em lineamentos morfotectônicos importando-se a tabela gerada no aplicativo $\operatorname{ArcGIS}{ }^{\circledR}$. A frequência das estruturas originou um diagrama de rosetas, que foi analisado para definição dos principais padrões de elementos lineares.

Após terem sido processadas as informações iniciou-se a análise dos dados hidrogeoquimicos, utilizando-se o programa $S P S S^{\circledR}$ versão 12 . Os dados hidroquimicos foram analisados empregando-se Análise Fatorial de Componentes Principais e Análise de Agrupamentos.

A Análise Fatorial de Componentes Principais (AFCP) foi utilizada para separar as fácies hidroquímicas no SASG. Esse processo possibilita transformar linearmente um conjunto de variáveis originais em um novo conjunto menor de variáveis não-correlacionadas, facilitando o manuseio e a compreensão do fenômeno, sem perda significativa de informação (Palácio, 2004).

A preparação da matriz de correlação busca padronizar os dados, normalizando para o valor de 1, mínimo eigenvalue aceito (Kaiser, 1958). A matriz de correlação obtida nem sempre é de fácil compreensão. Para suprimir essa limitação, usa-se o processo de rotação ortogonal da matriz original, gerando uma nova matriz de cargas fatoriais, que apresentam melhor significado interpretativo aos fatores (Andrade et al., 2007). A estrutura, que é obtida pelo método Varimax, inclui fatores dominantes, as variáveis e seus valores de comunalidade, que são as proporções da variância total de uma variável explicada pelos fatores totais (Fernandes et al., 2006).

A análise de agrupamentos (Cluster Analysis) é usada para caracterizar várias técnicas numéricas com objetivo de classificar valores de uma matriz de dados em grupos discretos (Landim, 2010).

No presente trabalho foi utilizado o método por agrupamentos hierárquicos, que é o mais utilizado em estudos geológicos e hidrogeológicos, através da metodologia de variância mínima (ward's method). Esse método consiste em obter uma matriz simétrica de similaridade a partir da matriz original, obtida através da AFCP. Esse tipo de metodologia busca detectar pares de casos com a mais alta similaridade ou mais baixa distância (Landim, 2003, 2010).

Os resultados da análise são organizados em gráficos que mostram as relações entre os grupos encontrados. A forma gráfica mais usada para re- 
presentar o resultado final é o dendrograma. Após a análise do dendrograma e separação em grupos hidrogeoquímicos distintos de água, esses grupos são projetados em gráficos das cargas de fatores principais, obtidos a partir da AFCP, elaborados no plano bidimensional.

Foram então gerados mapas de densidade de fraturas, que correspondem ao número de lineamentos que ocorrem em determinada área. Conceitualmente este cálculo consiste em um círculo desenhado ao redor de cada célula da imagem usando como raio um valor arbitrário informado nas propriedades da ferramenta. A porção do comprimento de cada lineamento que cai dentro da área circular é somada e o total dividido pela área do círculo (Oliveira et al., 2009). Assim, estruturas que estejam até o valor do raio de distância serão utilizadas no cálculo da densidade. 0 resultado são mapas de densidades de lineamentos, que são avaliados em função dos poços cadastrados anteriormente. Foram gerados mapas para a totalidade dos lineamentos e para cada grupo de direções e comprimento das fraturas.

Os dados geoquímicos das águas de cada agrupamento foram posteriormente cruzados com os lineamentos, com o objetivo de identificar padrões e correlações entre disposição espacial e a tectônica rúptil da área. As diferentes fácies de águas ainda foram plotadas no diagrama de Piper, através do programa Diagrammes, software livre disponibilizado pelo Laboratório de Hidrogeologia d'Avignon (Laboratoired'Hydrogéologie d'Avignon). No Diagrama de Piper, plotam-se os percentuais de mili-equivalentes por litro dos principais cátions e ânions de cada poço tubular. 0 programa também calculou o balanço iônico da água dos poços utilizados para as análises geoquímicas. Foram consideradas somente as análises em que a diferença entre os somatórios não fosse superior a 10\%.

\section{Resultados}

A extração dos lineamentos a partir de imagens de satélite na área em estudo permitiu definir e traçar um total de 1.981 lineamentos morfotectônicos. Para facilitar a interpretação dos resultados foram feitas filtragens de direção dos lineamentos, sendo confeccionado diagrama de rosetas e mapas de densidade de lineamentos.

A partir da representação da totalidade dos lineamentos foi reconhecido que as principais direções ilustradas pelo diagrama estatístico de roseta de frequência absoluta, são representadas pelos seguintes azimutes: $060^{\circ}$ a $070^{\circ}, 0$ a $015^{\circ}$ e $290^{\circ}$ a $315^{\circ}$ (Fig. 3). Foram definidas filtragens por direções, divididas em quatro grupos: N-NE $(0$ a $45^{\circ} / 180^{\circ}$ a $225^{\circ}$ ), NE-E (45ㅇ a $90^{\circ} / 225^{\circ}$ a $270^{\circ}$ ), NW-W (90ㅇ a $135^{\circ} / 270^{\circ}$ a $315^{\circ}$ ) e N-NW (135ㅇa a $180^{\circ} / 315^{\circ}$ a $360^{\circ}$ ) (Fig. 4).

Para facilitar acompreensão e a visualização dos mapas de densidade de lineamentos, estes foram divididos em três categorias:baixa, média e alta densidade de lineamentos.0 mapa da porção ocidental da área é o que apresenta maior densidade de lineamentos (alta densidade), sendo estes bem distribuídos por toda a Folha Chapecó. Já na Folha Erechim, predomina a densidade média. Como a totalidade da área apresenta elevado grau de fraturamento, apenas focos pontuais são reconhecidos comode densidade baixa.

Foram computadas 362 (18,3\%) estruturas de direção N-NE, como de área em estudo. Tais estruturas apresentam maior ocorrência na porção sudoeste da área, principalmente nos municípios de Palmeira das Missões, Dois Irmãos das Missões, Boa Vista das Missões, Jaboticaba, Seberi e Coronel Bicaco. Na direção NE-E foram reconhecidos 709 $(35,8 \%)$ lineamentos, que constituem o padrão de direção mais expressivo. Estas estruturas afetam de forma homogênea quase toda Folha Chapecó.

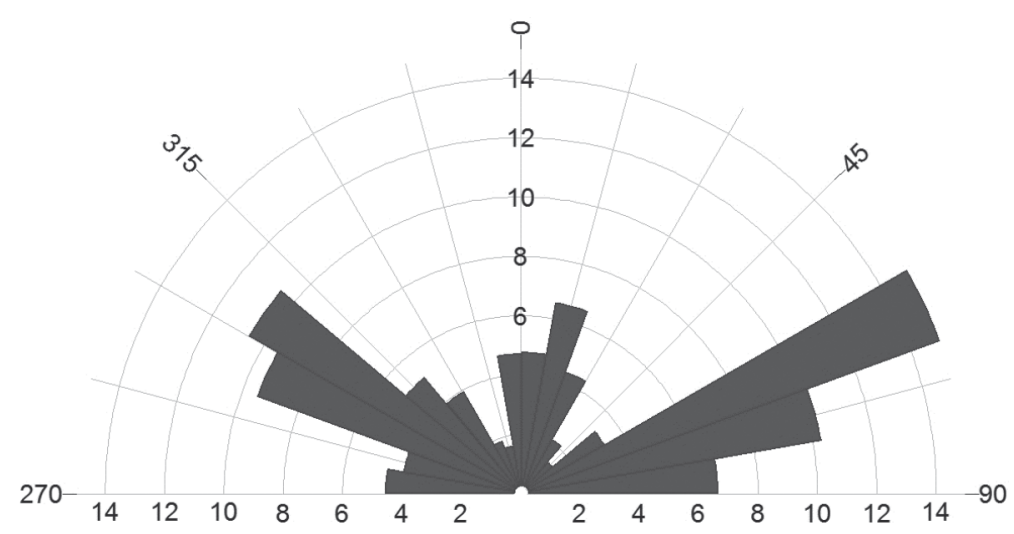

Figura 3. Diagrama estatístico de roseta da totalidade dos lineamentos em relação à frequência absoluta, indicando as principais direções dos lineamentos morfoestruturais na área de estudo. 
Na Folha Erechim, ocorrem focos de alta densidade, principalmente nos municípios de Erechim, Barão do Cotegipe, Paim Filho, Cacique Doble, São José do Ouro, Sananduva, Esmeralda e Getúlio Vargas. Segundo NW-W foram traçadas 623 (31,4 \%) estruturas, constituindo o segundo padrão com mais lineamentos na área em estudo, mostrando distribuição homogênea. A direção N-NW possui frequência bem menor que as demais direções, tendo sido registrados apenas 287 lineamentos (14,5 \%) homogeneamente distribuídos.

Para a caracterização hidrogeoquímica, foram inventariados 142 poços, que captam água do SASG, selecionados com base na consistência dos dados (balanço iônico). Foram descartados os poços que não continham na sua análise os cátions e ânions utilizados Diagrama Piper, resultando num conjunto de dados com os 13 seguintes parâmetros: cálcio, sódio, magnésio, potássio, bicarbonato, carbonato, cloreto e sulfato, flúor, $\mathrm{pH}$, dureza, STD e ferro. Os resultados da análise estatística através da AFCP permitiram o reconhecimento de quatro fatores distintos (Tab. 1).

Tabela 1. Matriz resultante da rotação da matriz original segundo o método Varimax.

\begin{tabular}{ccccc}
\hline \multirow{2}{*}{ Parâmetros } & \multicolumn{4}{c}{ Fatores } \\
\cline { 2 - 5 } & F1 & F2 & F3 & F4 \\
\hline $\mathrm{STD}$ & 0,873 & & 0,131 & \\
$\mathrm{pH}$ & 0,839 & $-0,293$ & & $-0,181$ \\
$\mathrm{Na}$ & 0,796 & $-0,387$ & 0,38 & \\
$\mathrm{CO}_{3}$ & 0,755 & $-0,434$ & & \\
Dureza & $-0,313$ & 0,92 & & \\
$\mathrm{Ca}$ & $-0,322$ & 0,883 & & \\
$\mathrm{Mg}$ & $-0,27$ & 0,861 & & \\
$\mathrm{HCO}$ & 0,344 & 0,746 & 0,233 & \\
$\mathrm{SO}_{4}$ & 0,13 & & 0,909 & \\
$\mathrm{Cl}$ & & 0,146 & 0,829 & \\
$\mathrm{~F}$ & 0,453 & & 0,512 & \\
$\mathrm{Fe}$ & 0,102 & & & 0,884 \\
$\mathrm{~K}$ & $-0,33$ & & & 0,767 \\
\hline
\end{tabular}

O Fator 1 (F1) contém STD, pH, $\mathrm{Na}$ e $\mathrm{CO}_{3}$ típicos de águas bicarbonatadas sódicas. No Fator 2 (F2), prevalecem a dureza, $\mathrm{Ca}, \mathrm{Mg}$ e $\mathrm{HCO}_{3}$, caracterizando águas bicarbonatadas cálcico-magnesianas. $\mathrm{O}$ Fator 3 (F3) contém $\mathrm{SO}_{4}, \mathrm{Cl}$ e $\mathrm{F}$ como íons principais, mostrando que o enriquecimento em flúor está relacionado com água sulfatadas e cloretadas. $\mathrm{O}$ último fator (F4) compreende os parâmetros Fe e K.

Para facilitar o entendimento desses fatores foi elaborada uma análise de agrupamento, apresentada sob forma de dendrograma, que permitiu o reconhecimento de cinco grupos distintos quimicamente de águas subterrâneas (Fig. 5). Tais grupos hidrogeoquímicos foram projetados em gráficos bidimensionais dos Fatores Principais, obtidos a partir da AFCP (Fig. 6).

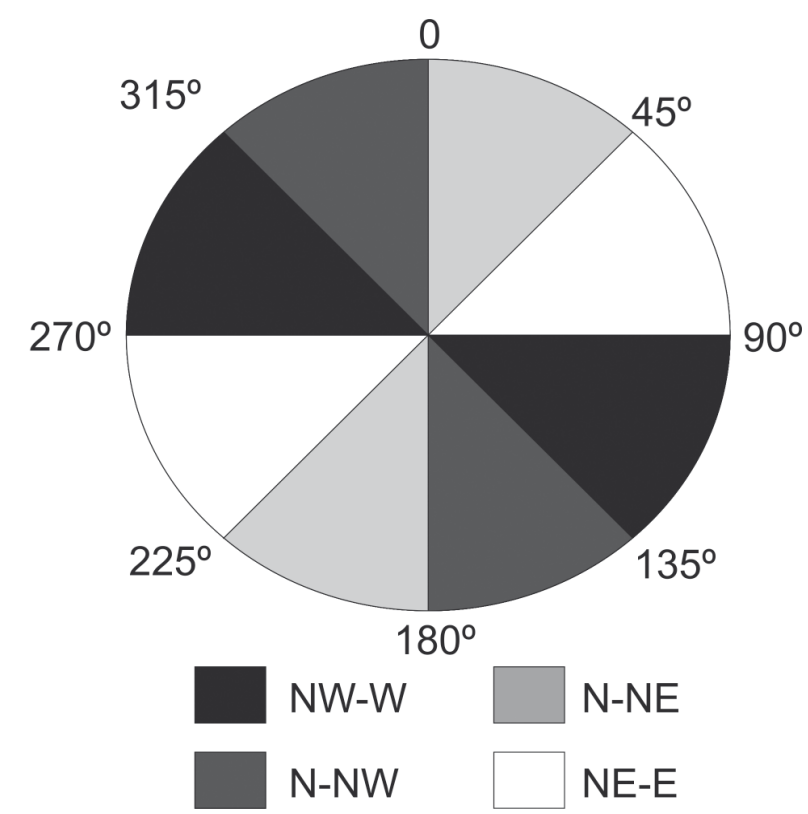

Figura 4. Grupos definidos por filtragens de direções.

A separação das amostras em grupos possibilitou interpretar melhor as características químicas e separar as fácies hidrogeoquímicas das águas da região. 0 Grupo 1é fortemente relacionado com o F2. 0 Grupo 2apresenta relação com o F4. 0 Grupo 3 apresenta forte relação positiva com o F1 e relação negativa com o F2. 0 Grupo 4 é ligado ao F3 e reduzido no F4. Por último, o Grupo 5 não apresenta correlação positiva com nenhum fator, mas possui correlação negativa com o F1 e F2.

Para facilitar a interpretação e organizar de forma mais eficiente e simplificada os dados obtidos na análise estatística, os grupos foram nomeados conforme os resultados obtidos. 0 Grupo 1 foi denominado de fácies $\mathrm{CaMg}$, o Grupo 2 de fácies FeK, o Grupo 3 de fácies Na, o Grupo 4 de fácies $\mathrm{F}$ e o Grupo 5 de fácies Águas Mistas (AM).

Os cinco grupos de águas foram plotados no diagrama de Piper para relacionar o tratamento estatístico com a geoquímica das águas subterrâneas da região. Quando classificadas no diagrama de Piper (Fig. 7), as águas da fácies CaMg são exclusivamente bicarbonatadas em termos de ânions, entretanto,considerando apenas os cátions, predominam as águas cálcicas ou magnesianas e em menor quantidade sódicas, representando $86 \% \mathrm{e}$ $14 \%$, respectivamente. A fácies FeK predomina nas 


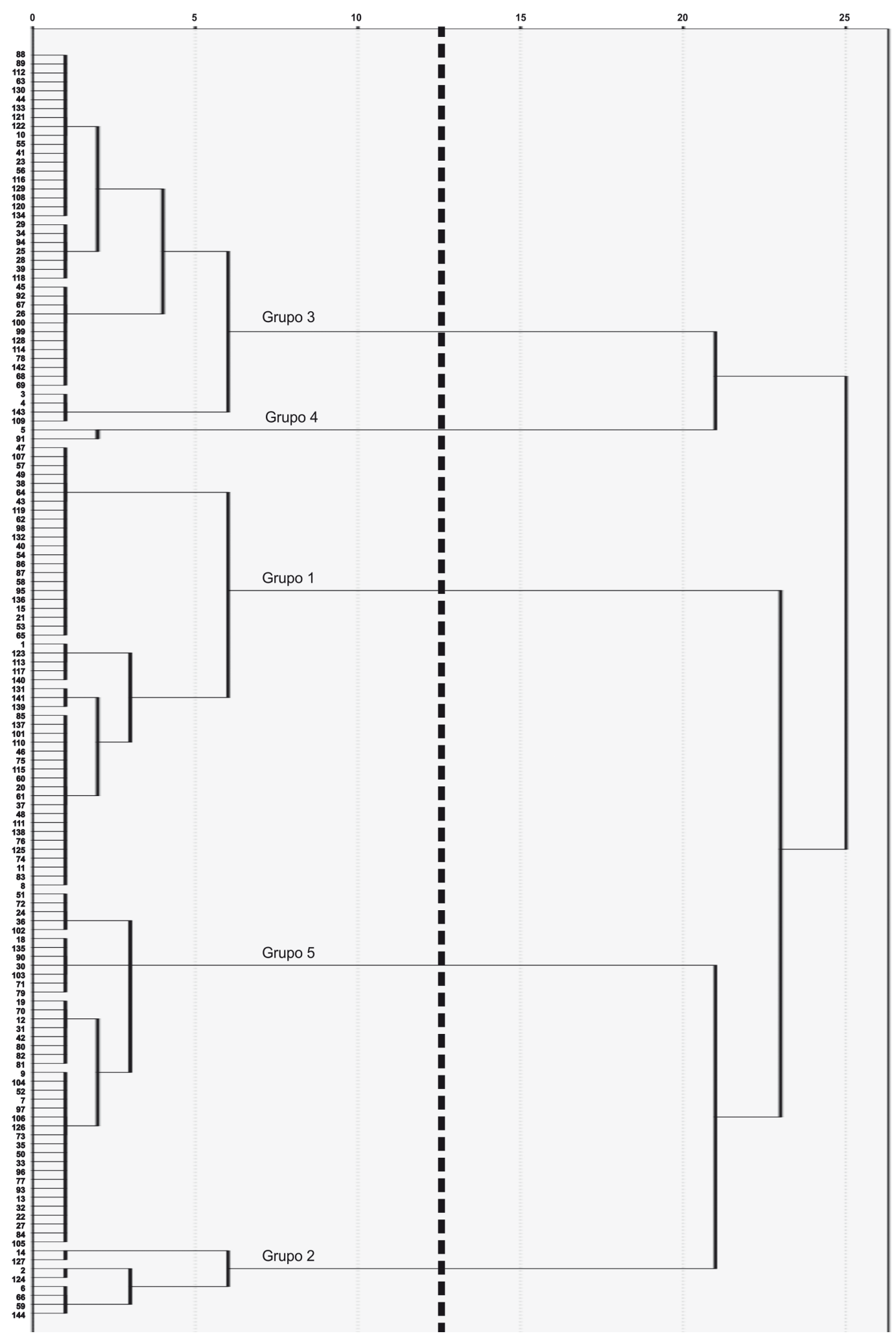

Figura 5. Dendrograma representando cinco distintos grupos geoquímicos de água. 


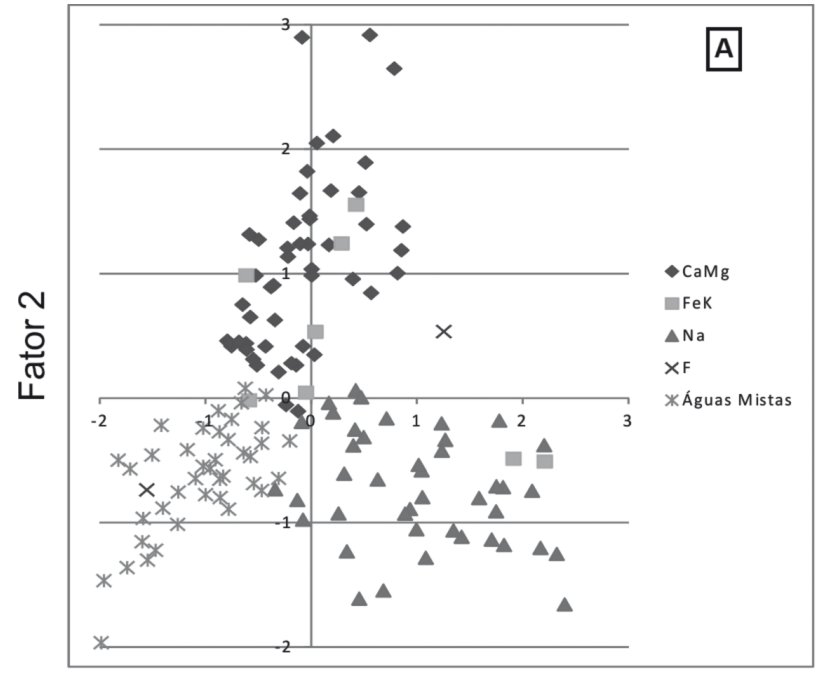

Fator 1

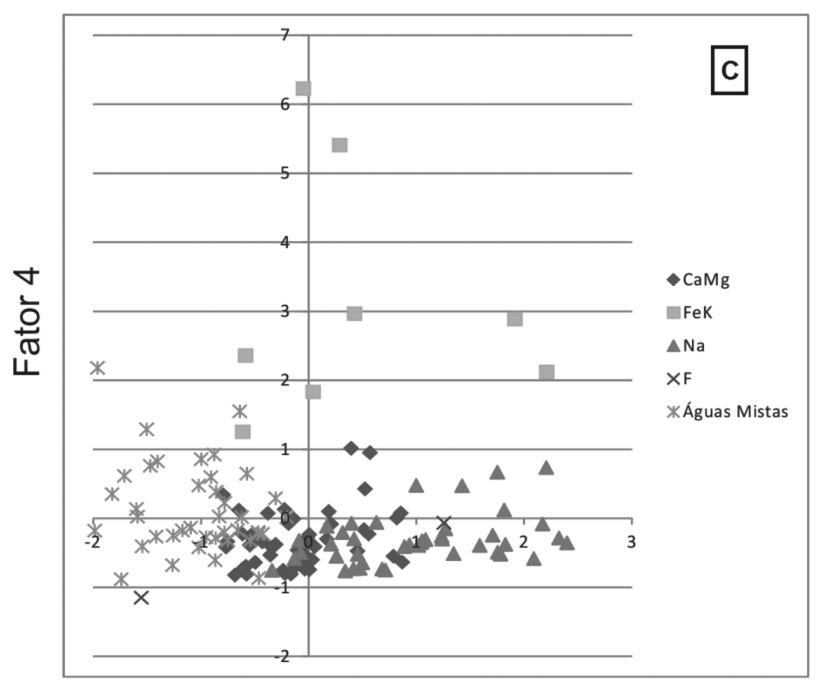

Fator 1

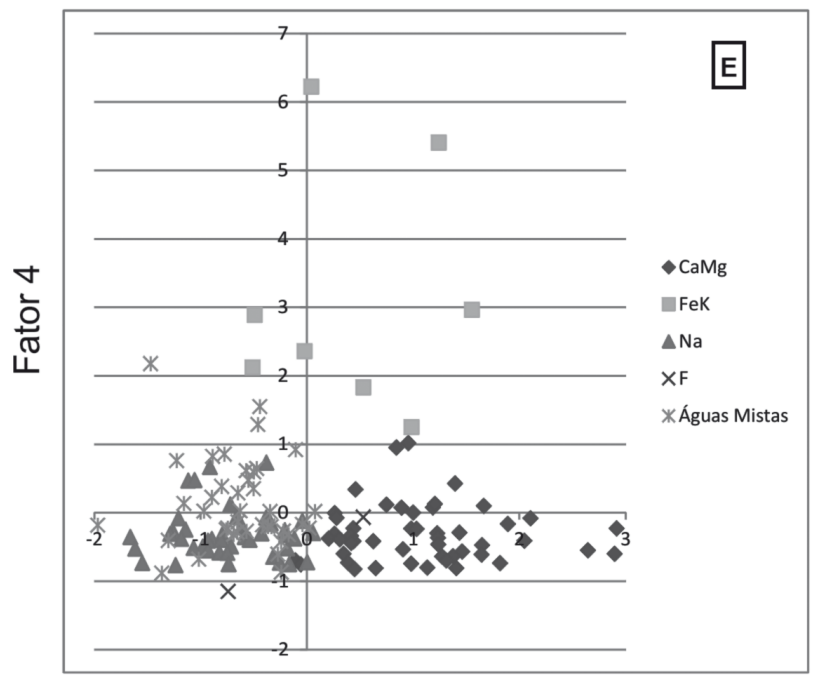

Fator 2

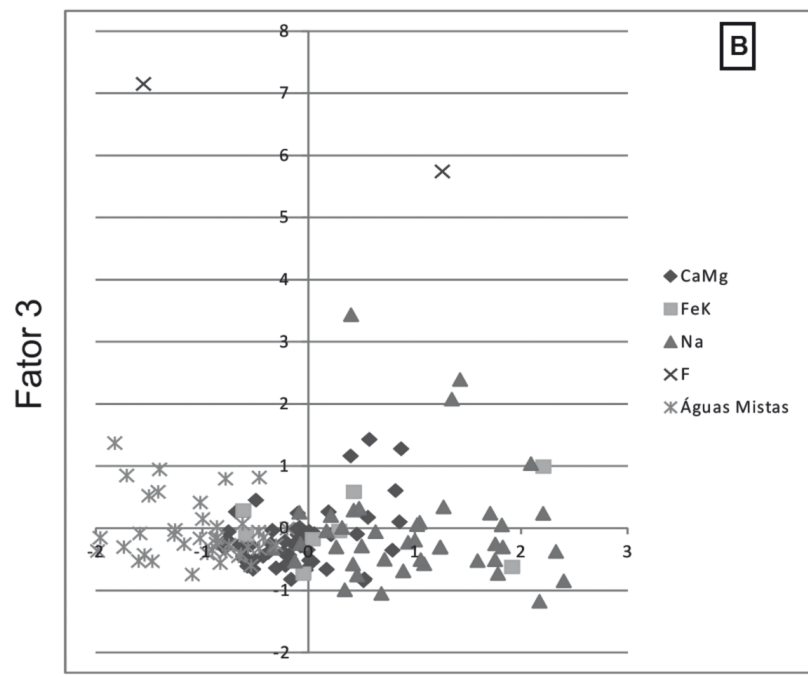

Fator 1

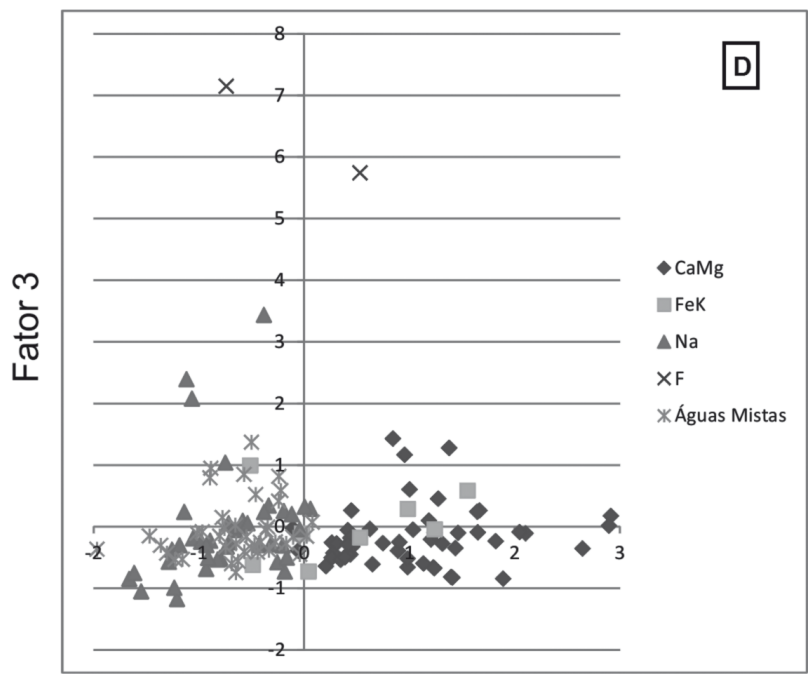

Fator 2

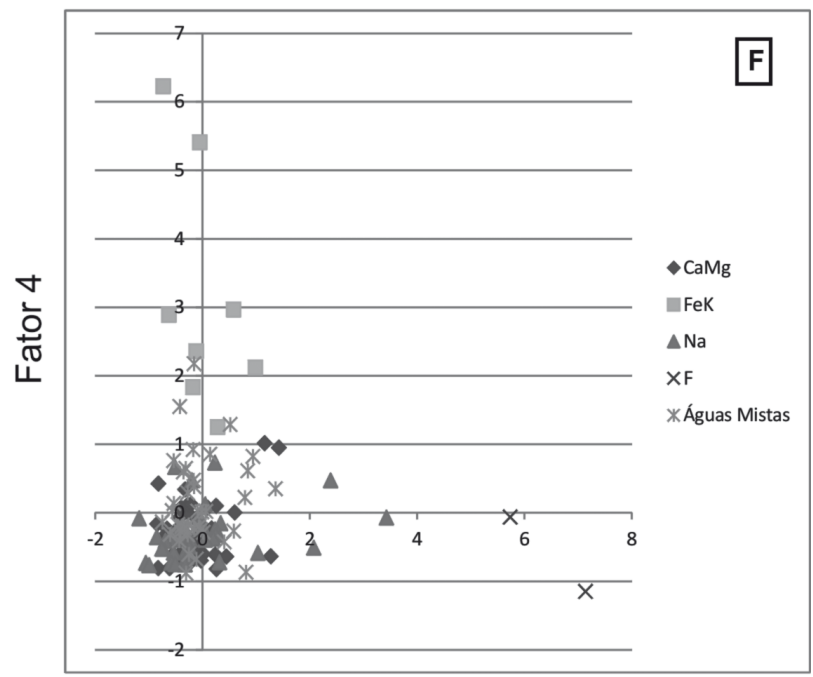

Fator 3

Figura 6. Gráficos bidimensionais projetando os grupos geoquímicos de água, conforme as cargas dos fatores obtidos na AFCP. A) Fator 1 x Fator 2; B) Fator 1 x Fator 3; C) Fator 1 x Fator 4; D) Fator 2 x Fator 3; E) Fator 2 x Fator 4; F) Fator 3 x Fator 4. 
águas bicarbonatadas cálcicas ou magnesianas, contemplando $75 \%$ dos poços. 0 restante $(25 \%)$ apresenta características bicarbonatadas sódicas. A fácies Na representa $100 \%$ dos poços com águas bicarbonatadas sódicas, enquanto as águas da fácies $\mathrm{F}$ são fortemente sódicas, porém apresentam caráter misto no tocante aos ânions, tendo 50\% das águas caráter sulfatado ou cloretado e a outra metade bicarbonatada. No diagrama de Piper, as águas dafácies AM são classificadas de forma similar às da fácies $\mathrm{CaMg}$ e fácies $\mathrm{FeK}$, predominando os tipos bicarbonatados cálcicos ou magnesianos (80 \%) e, subordinadamente, os tipos bicarbonatados sódicos (20\%).

Integrando os dados obtidos na etapa de análise estatística com a classificação hidrogeoquímica das águas, foi observado que as duas primeiras fácies descritas anteriormente ( $\mathrm{CaMg}$ e $\mathrm{FeK}$ ) e a fácies AM apresentam características de águas bicarbonatadas cálcicas ou magnesianas. A fácies CaMgexibe uma distribuição homogêneano diagrama de Piper e apresenta altos valores de Dureza contrastando coma fácies AM, que possui uma distribuição mais aleatória no mesmo diagrama e caracteriza-se por apresentar baixos valores de Dureza.Essas três fácies possuem características mais ácidas e pouco salinas. 0 grupo de águas bicarbonatadas sódicas (fácies $\mathrm{Na}$ ) apresenta caráter alcalino e salinidade mais elevada. As amostras da fácies F são claramente isoladas quando plotadas no diagrama de Piper, se comparadas aos outros grupos de fácies hidroquímicas. A distribuição sustenta a associação de águas sulfatadas com o flúor, tendo como atributo importante o caráter sódico e empobrecimento em potássio e ferro.

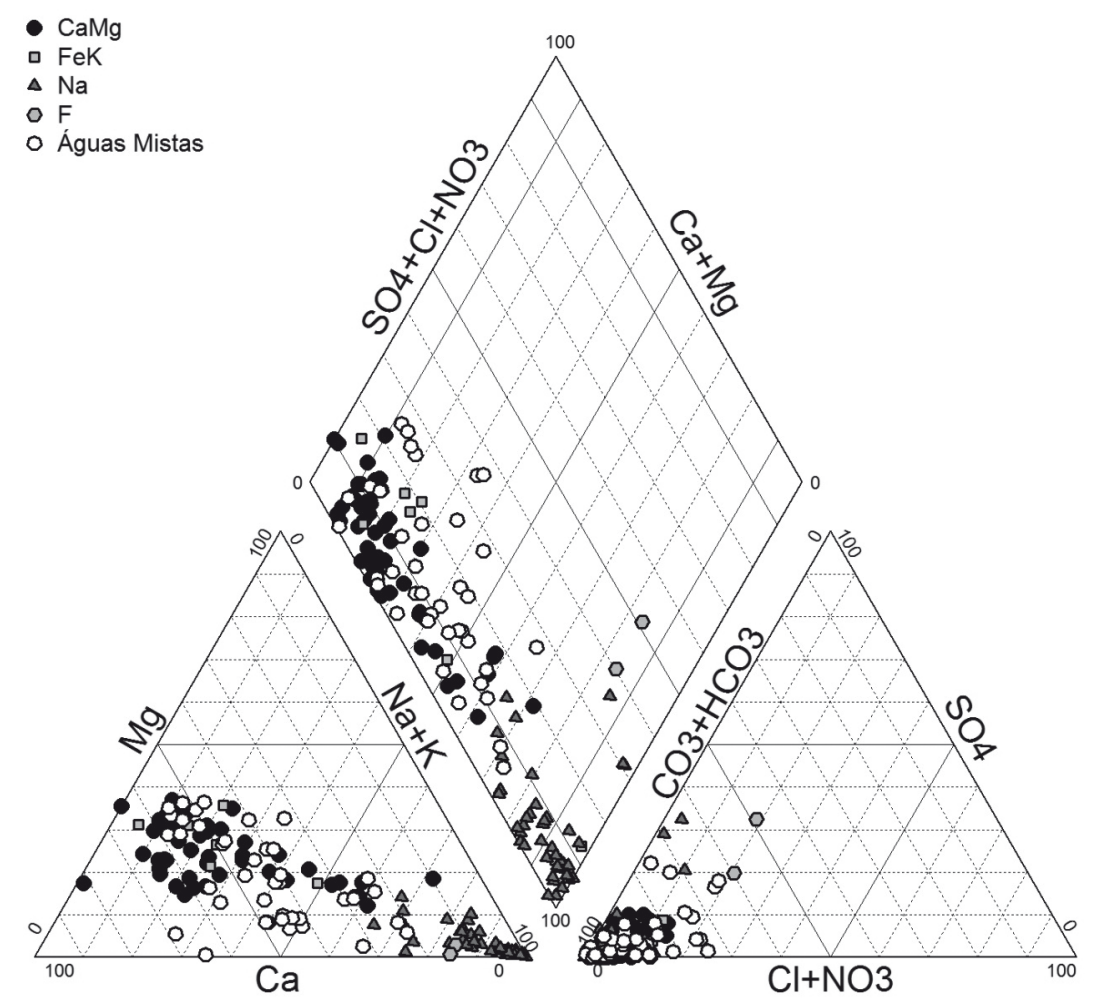

Figura 7. Fácies hidrogeoquímicas plotadas no Diagrama de Piper.

\section{Discussão dos resultados}

O cruzamento de dados, da análise estrutural e da hidrogeoquímica dos poços, permitiu relacionar as estruturas, densidade de lineamentos e os grupos geoquímicos de águas da região do Alto Rio Uruguai (Figs. 8 e 9).

Todas as fácies hidroquímicas encontradas na região do estudo possuem uma forte correlação positiva com áreas de alta densidade de lineamen- tos (Fig. 8 e tab.2).

A tabela 3 demonstra que a fácies CaMg apresenta maior incidência nas áreas de alta densidade dos lineamentos NE-E e N-NW, com 50\% e 56\% dos poços, respectivamente. As águas da fácies $\mathrm{FeK}$ e fácies $\mathrm{Na}$ estão concentradas nos lineamentos NE-E e NW-W. É importante salientar que, segundo Cunha (2010), essas direções de lineamentos (NEE e NW-W) são as direções que apresentam os poços mais produtivos da região do Alto Rio Uruguai. 
A fácies $\mathrm{F}$ encontra-se restrita à região próxima ao Rio Uruguai, situando-se em zonas de alta densidade de lineamentos N-NE. Não obstante, este dado possui pequeno significado, considerando-se a existência de somente dois poços. A fácies Águas Mistas apresentou maior incidência nos lineamentos de direção NW-W.

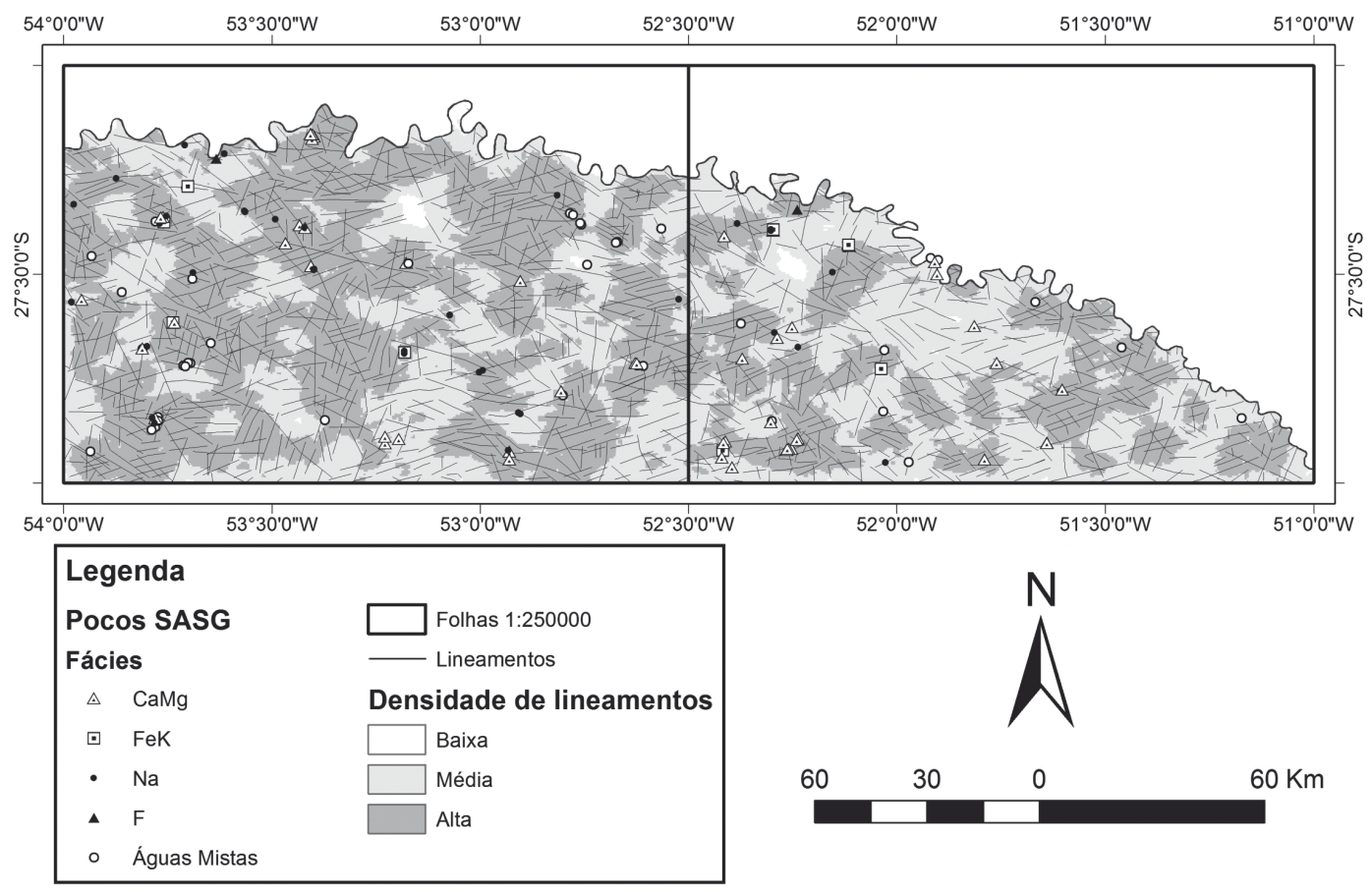

Figura 8. Distribuição espacial e densidade da totalidade de lineamentos comparadas com as fácies hidrogeoquímicas dos poços.

Tabela 2. Estatística do posicionamento dos poços, segundo as fácies hidrogeoquímicas, com a densidade dos lineamentos tectônicos.

\begin{tabular}{|c|c|c|c|c|}
\hline \multirow{3}{*}{ Fácies } & \multirow{3}{*}{ Poços } & \multicolumn{3}{|c|}{ Densidade de lineamentos } \\
\hline & & \multicolumn{3}{|c|}{ Totalidade de Lineamentos } \\
\hline & & Baixa & Média & Alta \\
\hline \multirow{2}{*}{$\mathrm{CaMg}$} & $\mathrm{n}$ ㅇ. & 0 & 12 & 38 \\
\hline & $\%$ & 0,0 & 24,0 & 76,0 \\
\hline \multirow{2}{*}{$\mathrm{FeK}$} & $\mathrm{n} \stackrel{0}{ }$. & 0 & 2 & 6 \\
\hline & $\%$ & 0,0 & 25,0 & 75,0 \\
\hline \multirow{2}{*}{$\mathrm{Na}$} & $\mathrm{n} \stackrel{0}{ }$. & 0 & 6 & 36 \\
\hline & $\%$ & 0,0 & 14,3 & 85,7 \\
\hline \multirow{2}{*}{$\mathrm{F}$} & $\mathrm{n}$ ㅇ. & 0 & 0 & 2 \\
\hline & $\%$ & 0,0 & 0,0 & 100,0 \\
\hline Águas & $\mathrm{n}$ ㅇ. & 1 & 12 & 27 \\
\hline Mistas & $\%$ & 2,5 & 30,0 & 67,5 \\
\hline
\end{tabular}

Não foi evidenciada correlação entre o comprimento das estruturas e a composição das águas.

Cunha (2010), através de mapa potenciométrico na mesma área de estudo, indicou que o fluxo regional das águas subterrâneas se faz na direção do Rio Uruguai, de sudeste para noroeste. É de se registrar que, comparando esse mapa potenciométrico e a distribuição espacial dos poços deste trabalho, as fácies CaMg e fácies AM se distribuem predominantemente em áreas de recarga do SASG. Os dados hidrogeoquímicos obtidos no presente estudo sugerem que estas águas possuem baixo tempo de residência e se relacionam com a recarga pluviométrica, demonstrada pelos valores mais baixos de $\mathrm{pH}$ e STD. As fácies FeK e fácies F apresentam distribuição predominante em áreas de descarga e/ou recarga ascendente do SAG. Por outro lado, as águas da fácies $\mathrm{Na}$ possuem valores de pH mais alcalino, baixa dureza e elevado STD, que sugerem características de águas com maior tempo de residência e com possível mistura com águas provenientes do SAG subjacente. Essa distribuição é concordante com os estudos de Nanni (2008), Nanni et al. (2008, 2009) e Freitas et al. (2012), que apresentaram uma interpretação sobre a interação de águas ascendentes do SAG, para representar essas fácies mais diferenciadas do SASG. 


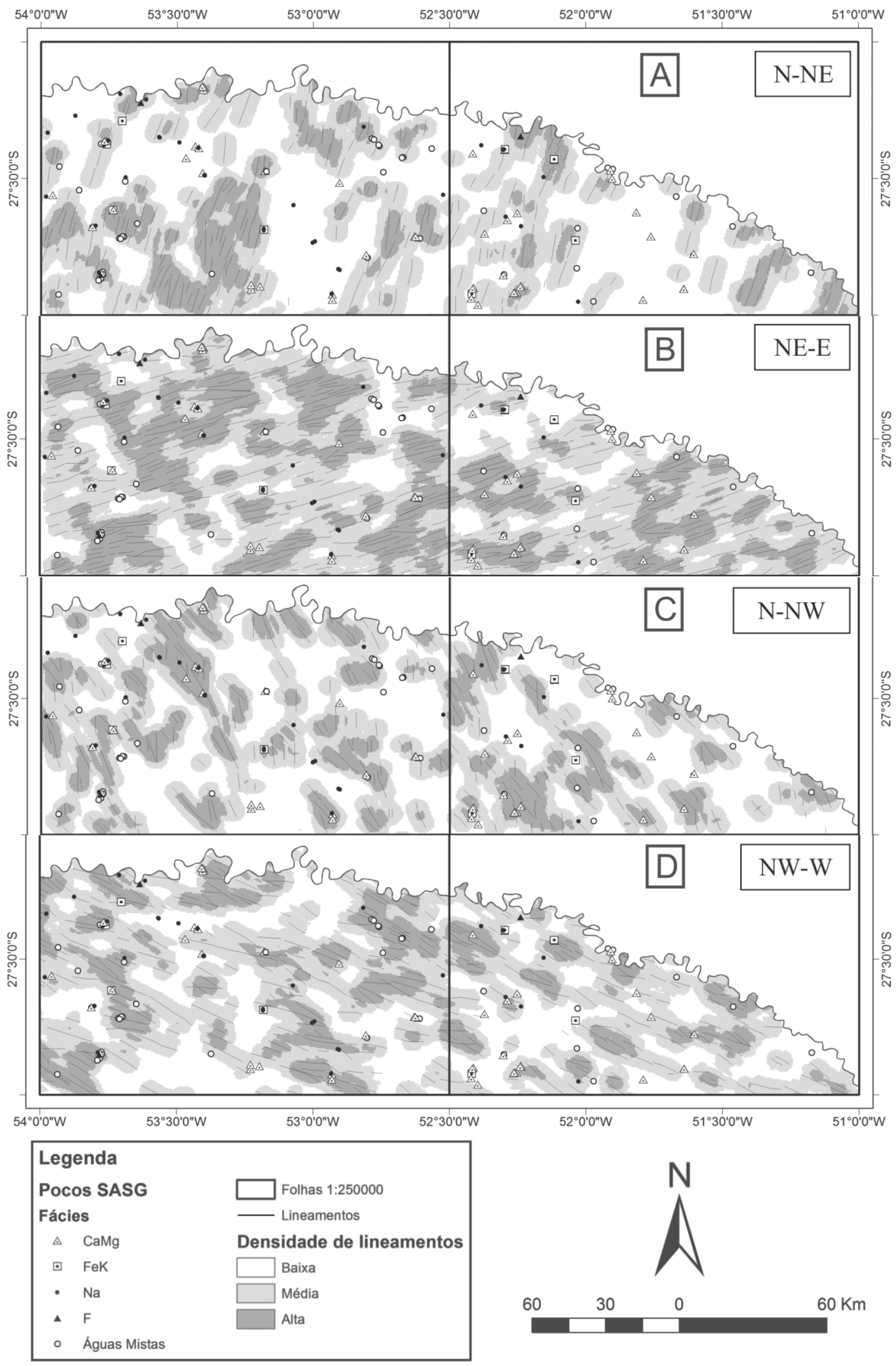

Figura 9. Distribuição espacial e densidade dos lineamentos das direções preferenciais comparados com as fácies hidrogeoquímicas das águas. A) N-NE; B) NE-E; C) N-NW; D) NW-W.

\section{Conclusões}

O tratamento estatístico dos dados hidrogeoquímicos através da AFCP permitiu o reconhecimento de quatro fatores distintos de águas subterrâneas. Para facilitar o entendimento desses fatores foi elaborada uma análise de agrupamento, apresentado sob forma de dendrograma, que separou as águas do SASG, na região noroeste do Rio Grande do Sul, em cinco grupos distintos quimicamente (fácies $\mathrm{CaMg}$, fácies $\mathrm{FeK}$, fácies $\mathrm{Na}$, fácies $\mathrm{F} \mathrm{e}$ fácies Águas Mistas).
A análise de 1.981 lineamentos morfotectônicos a partir de imagens de satélites demonstrou a existência de quatro direções principais de faturamento, predominando as orientações NE-E e NWW.

A integração dos dados e a comparação entre a distribuição das fácies hidrogeoquímicas e os elementos estruturais mostrou correlações evidentes entre a densidade de lineamentos e os grupos químicos. Os lineamentos de direção NE-E e $\mathrm{N}-\mathrm{NW}$ se correlacionam predominantemente com a fácies CaMg. As fácies FeK e fácies Na apresentam 
Tabela 3. Posicionamento dos poços, segundo as fácies hidrogeoquímicas, com a direçãoe a densidade dos lineamentos morfotectônicos.

\begin{tabular}{|c|c|c|c|c|c|c|c|c|c|c|c|c|c|}
\hline \multirow{3}{*}{ Fácies } & \multirow{3}{*}{ Poços } & \multicolumn{12}{|c|}{ Densidade de lineamentos } \\
\hline & & \multicolumn{3}{|c|}{ NE-E } & \multicolumn{3}{|c|}{$\mathrm{N}-\mathrm{NE}$} & \multicolumn{3}{|c|}{$\mathrm{N}-\mathrm{NW}$} & \multicolumn{3}{|c|}{ NW-W } \\
\hline & & Baixa & Média & Alta & Baixa & Média & Alta & Baixa & Média & Alta & Baixa & Média & Alta \\
\hline \multirow{2}{*}{ CaMg } & no. & 4 & 21 & 25 & 19 & 16 & 15 & 14 & 8 & 28 & 16 & 15 & 19 \\
\hline & $\%$ & 8,0 & 42,0 & 50,0 & 38,0 & 32,0 & 30,0 & 28,0 & 16,0 & 56,0 & 32,0 & 30,0 & 38,0 \\
\hline \multirow{2}{*}{ FeK } & no. & 3 & 1 & 4 & 1 & 5 & 2 & 4 & 1 & 3 & 3 & 1 & 4 \\
\hline & $\%$ & 37,5 & 12,5 & 50,0 & 12,5 & 62,5 & 25,0 & 50,0 & 12,5 & 37,5 & 37,5 & 12,5 & 50,0 \\
\hline \multirow{2}{*}{$\mathrm{Na}$} & no. & 2 & 18 & 22 & 20 & 15 & 7 & 14 & 16 & 12 & 7 & 12 & 23 \\
\hline & $\%$ & 4,8 & 42,9 & 52,4 & 47,6 & 35,7 & 16,7 & 33,3 & 38,1 & 28,6 & 16,7 & 28,6 & 54,8 \\
\hline \multirow{2}{*}{$\mathbf{F}$} & no. & 0 & 2 & 0 & 0 & 0 & 2 & 2 & 0 & 0 & 0 & 2 & 0 \\
\hline & $\%$ & 0,0 & 100,0 & 0,0 & 0,0 & 0,0 & 100,0 & 100,0 & 0,0 & 0,0 & 0,0 & 100,0 & 0,0 \\
\hline Águas & no. & 12 & 14 & 14 & 9 & 21 & 10 & 14 & 18 & 8 & 8 & 8 & 24 \\
\hline Mistas & $\%$ & 30,0 & 35,0 & 35,0 & 22,5 & 52,5 & 25,0 & 35,0 & 45,0 & 20,0 & 20,0 & 20,0 & 60,0 \\
\hline
\end{tabular}

relação com as direções NE-E e NW-W. A fácies F está fortemente relacionada com os lineamentos N-NE e a fácies AM com a direção NW-W.

As fácies CaMg e AM apresentam características de baixo tempo de residência, estando relacionadas às áreas de recarga do SASG, possuindo valores mais baixos de $\mathrm{pH}$ e STD. A fácies Na apresenta valores de $\mathrm{pH}$ alcalino, baixa dureza e elevado STD, o que sugere misturas com águas provenientes do SAG subjacente. A fácies FeK e a fácies F estão mais relacionadas com zonas de descarga e/ ou recarga ascendente do SAG.

\section{Referências}

Andrade, E.M., Araújo, L.F.P., Rosa, M.F., Disney, W. \& Alves, A.B. 2007. Seleção de indicadores da qualidade das águas superficiais pelo emprego de análise multivariada. Engenharia Agrícola, 27 (3): 683-690.

CPRM. Serviço Geológico do Brasil. 2005. Mapa Hidrogeológico do Estado do Rio Grande do Sul. Porto Alegre, CPRM - Serviço Geológico do Brasil, Governo do Estado do Rio Grande do Sul, SOPS - Secretária de Obras Públicas e Saneamento, SEMA - Secretária do Meio Ambiente, DRH - Departamento de Recursos Hídricos, escala: 1:750.000. Disponível em: <http:// www.cprm.gov.br/publique/media/mapa_hidrogeologico_RS.pdf>. Acesso em: 28/03/2011.

CPRM. Serviço Geológico do Brasil. 2006. Mapa Geológico do Estado do Rio Grande do Sul. Porto Alegre. Projeto Geologia do Brasil ao Milionésimo - Programa Geologia do Brasil, CPRM - Serviço Geológico do Brasil, escala: 1:750.000. Disponível em: <http:// www.cprm.gov.br/publique/media/mapa_rio_grande_sul.pdf>. Acesso em: 28/03/2011.

Cunha, G.G. 2010. Caracterização estrutural e hidrogeológica dos Sistemas Aquíferos Guarani e Serra Geral na região do Alto Uruguai, noroeste do Rio Grande do Sul. Porto Alegre, 86p. Monografia de Conclusão de Curso. Curso de Geologia, Instituto de Geociências,
Universidade Federal do Rio Grande do Sul.

Fernandes, M.A.B., Santiago, M.M.F., Mendes Filho, J., Silva, C.M.S.V., Frischkorn, H. \& de Lima, J.O.G. 2006. Análise estatística aplicada em amostras de água subterrânea no município de Caucaia. In: CONGRESSO BRASILEIRO DE ÁGUAS SUBTERRÂNEAS, 14, 2006, Curitiba, Anais...Curitiba, ABAS, 16p. CD-ROM.

Freitas, M.A. \& Machado, J.L.F. 2000. Hydrochemistry of Serra Geral Aquifer in Western Santa Catarina State. In: CONGRESSO MUNDIAL INTEGRADO DE ÀGUAS SUBTERRÂNEAS,1, 2000, Fortaleza, Anais...,Fortaleza, ABAS/AHLSUD/IAH,CD-ROM.

Freitas, M.A., Binotto, R.B., Nanni, A.S., Rodrigues, A.L.M. \& Bortoli, C.R. 2012. Avaliação do potencial hidrogeológico, vulnerabilidade intrínseca e hidroquímica do Sistema Aquífero Serra Geral no noroeste do Estado do Rio Grande do Sul. Revista Brasileira de Recursos Hídricos, 17(2): 31-41.

Kaiser, H.F. 1958. The Varimax Criterion for Analytic Rotation in Factor Analysis. Psychometrika, 23(3): 187-200.

Landim, P.M.B. 2003. Análise estatística de dados geológicos. $2^{\text {a }}$ ed., São Paulo, UNESP, 253p.

Landim, P.M.B. 2010. Introdução à análise estatística de dados geológicos multivariados. Rio Claro, UNESP. Disponível em: <http://www.rc.unesp.br/igce/aplicada/textodi.html>. Acesso em: 20/11/2011.

Lisbôa, N.A. 1996. Fácies, estratificações hidrogeoquímicas e seus controladores geológicos em unidades hidrogeológicas do Sistema Aquífero Serra Geral na Bacia do Paraná, Rio Grande do Sul.Porto Alegre, 135p. Tese de Doutorado, Programa de Pós-Graduação em Geociências, Instituto de Geociências, Universidade Federal do Rio Grande do Sul.

Nanni, A.S. 2008. O flúor em águas do Sistema Aquífero Serra Geral no Rio Grande do Sul: origem e condicionamento geológico. Porto Alegre, 127p. Tese de Doutorado, Programa de Pós-Graduação em Geociências, Instituto de Geociências, Universidade Federal do Rio Grande do Sul.

Nanni, A.S., Roisenberg, A., Fachel, J.M.G., Mesquita, G. \& 
Danieli, C. 2008. Fluoride characterization by principal component analysis in the hydrochemicalfácies of Serra Geral Aquifer System in Southern Brazil.Anais da Academia Brasileira de Ciências,80(4): 693-702.

Nanni, A.S., Roisenberg, A., Marimon, M.P.C. \& Viero, A.P. 2009. The hydrochemical facies and anomalous fluoride content in the Serra Geral aquifer system, southern Brazil: a GIS approach with tectonic and principal component analysis. Environmental Geology, 58(6): 1247-1255

Oliveira, D.B., Moreno, R.S., Miranda, D.J., Ribeiro, C.S., Seoane, J.C.S. \& Melo, C.L. 2009. Elaboração de um mapa de lineamento estrutural e densidade de lineamento através de imagem SRTM, em uma área ao norte do rio Doce, ES. In: SIMPÓSIO BRASILEIRO DE SENSORIAMENTO REMOTO, 14, 2009, Natal. Anais... Natal, INPE, p. 4157-4163.

Man 539

Editores: Lauro V. S. Nardi \& Maria do Carmo Lima e Cunha.
Palácio, H.A.Q. 2004. Índice de qualidade das águas na parte baixa da bacia hidrográfica do rio Trussu, Ceará. Fortaleza, 96p. Dissertação de Mestrado, Programa de Pós-Graduação em Engenharia Agrícola, Universidade Federal do Ceará.

Peate, D.W., Hawkesworth, C.J., Mantovani, M.S.M., Schukowski, W. 1990. Mantle plumes and flood-basalt stratigraphy in the Paraná, South America. Geology, 18: 1223-1226.

Peate, D.W., Hawkesworth, C.J., Mantovani, M.S.M. 1992. Chemical stratigraphy of the Paraná lavas (South America): classification of magma types and their spatial distribution. Bulletin of Volcanology, 55: 119139.

USGS. U.S. Geological Survey. 2000.Shuttle Radar Topography Mission.Washington, NASA-USGS. Disponível em: <http://srtm.usgs.gov/>. Acesso em: 03/05/2011. 
